\title{
COORDINATION IN A SUPPLY CHAIN FOR BULK CHEMICALS
}

\author{
Henk de Swaan Arons \\ Eelco van Asperen \\ Rommert Dekker \\ Mark Polman \\ Burgemeester Oudlaan 50 \\ Erasmus School of Economics \\ Rotterdam, 3062 PA, THE NETHERLANDS
}

\begin{abstract}
A chemical plant in The Netherlands uses large annual supplies of a bulk chemical. A number of suppliers deliver their parcels from overseas by short sea vessel to a transshipment point where they are stored using a tank farm. Transportation from the transshipment point to the plant takes place by barge. Coordination of the schedules of vessels and barge provides the opportunity for board to board loading. Board to board loading provides clear benefits for the plant's operator, as it requires less handling and intermediate storage at the transshipment point. We demonstrate this by experiments conducted with a simulation model. The results are confirmed by analytical means.
\end{abstract}

\section{INTRODUCTION}

A supply chain can be characterized by four drivers, viz. facilities (such as plants, warehouses), transportation (different modes), (product) inventories and information (Chopra and Meindl 2004). Bulk chemicals are characterized by high volumes of liquids, which are transported by pipelines, tank trucks, rail wagons, and ships: the inventories are stored in tanks. Several manufacturing stages exist, e.g., one producer makes bulk raw materials which are further processed by other producers whose products are in turn used by other manufacturers.

Proximity to users of bulk chemicals, such as car manufacturers, and cheap transport of supply are essential aspects in location decisions of chemical plants. Usually the bulk of supply and sales for a chemical plant occurs within a single continent, with occasional imports or exports to other continents.

As many chemical products have commodity characteristics, there is severe price competition. However, the number of suppliers and users is limited, and prices are not always listed on markets. Hence, from a strategic/cost perspective, it seems wise to use several suppliers instead of one. However, scheduling deliveries among multiple suppliers is hard, which negatively impacts the logistical process.

In this paper, we consider the case of an inland bulk chemical plant in the Netherlands trying to improve its supply chain. The plant's domestic supply can be arranged by pipeline, train, truck or barge, depending on the proximity of the supplier. Alternatively, several suppliers may transport by ship to a port, where they transship their products into tanks using a third party tank farm. Inland transport from this transshipment point occurs either by pipeline, truck, train or barge. Tankage is available in flexible amounts at a third party tank farm in a port. This provides a buffer for any uncertainty in the supply coming from sea transport. Further inland transport is more or less controlled by the plant, which allows it to limit the amount of dedicated tankage at its site.

The plant decided on a transition of its inland transport mode from truck to barge. Barge transport has several advantages: it is cheaper, safer and does not create dangerous transports through populated areas. Barge transport, however, causes larger lots to be transported, requires investment in jetties and pipelines, and is restricted to waterways only.

Barges sail back and forth from the plant to a transshipment point where short sea vessels deliver their parcels from overseas. When the company decided to make the move to supply by barge it also wanted to assess the performance of its supply chain, limit the number of suppliers somewhat and increase the probability of direct-on transport by so-called board to board loading from sea ship to inland barge. This is cheaper as it bypasses the tank farm.

For reasons of presentation, some of the details of the case presented in this paper have been omitted. The actual plant uses several bulk chemicals. Because the products are used in fixed proportions and are delivered using the same vessels and barges, we have created a standard product mix. We will refer to this product mix as a 'bulk chemical'.

In the next section relevant literature on this subject is reviewed. In section 3 a conceptual model of a supply 
chain for bulk chemicals is given. This model is applied to a case study in section 4. A simulation model based on this case study is outlined in section 5. For this paper, the simulation model is then used in section 6 to assess the probability of board to board loading and the effect of tighter delivery scheduling on this probability. The results of the simulation experiments are compared with analytical calculations. In section 7 we draw conclusions.

\section{LITERATURE REVIEW}

The topic of logistics planning in bulk chemicals has received little attention in scientific literature. Literature dealing with inventory and supply chain management tends to focus on a supplier's perspective, where one supplier has to move products to many customers. In the current situation, however, one customer (the chemical plant) receives products from several suppliers. In order to minimize logistic costs and increase reliability, it strives for increased control over its suppliers. Therefore, this supply chain has to be looked at from a customer's point of view.

Nieboer and Dekker (1995) discuss a model for tankage assessment (i.e., determining how much storage capacity is needed) and stock control in refineries. They consider a tank that is continuously fed by a production unit and two types of demand. First, there is a demand for large parcels, which is planned in advance. Second, there is demand for small parcels, modeled by a Poisson process. The difference between the inflow from production and the outflow from small demands is modeled as a Brownian motion. Silver and Peterson (1985) present a decision rule that can be applied to calculate the required safety stock, given a certain probability of stock out during a replenishment cycle. However, this rule is based on variability in demand, not in supply. Newhart, Scott and Vasko (1993) discuss a simple method for incorporating the variability in supply within the variability of demand. However, this method assumes normality of demand and lead times. Haehling von Lanzenauer, James, and Wright (1992) use a stochastic process approach to calculate the probability of insufficient supply (stock out) of natural gas, which is essentially risk analysis. In this case, the authors use the concept of a Design Day; a date for which extreme demand is assumed. Van Asperen et al. (2003a) describe the role of arrival processes in a port simulation and demonstrate the impact of increased coordination in terms of ship waiting times and required storage capacity.

All in all, these references give us little help in tackling the problem. Other relevant results may be found in the supply chain literature. Sometimes it is advocated to reduce the number of suppliers in order to improve coordination in the supply chain (e.g. shorter response time, collaborative planning and forecasting) or at least to carefully consider the number of suppliers needed in the presence of risks (Berger, Gerstenfeld, and Zeng 2004). In the present case, using a supplier that is located in close proximity to the plant would greatly simplify the logistics. Yet, the product under consideration is a commodity for which price competition exist. Multiple suppliers are used in order to get the lowest price and to keep several supply chain options open. The advantages of having multiple suppliers have to outweigh the associated logistical problems. How to achieve this has received little attention in literature.

\section{A CONCEPTUAL MODEL}

In this section a model is presented in order to help understand the dynamics of a simple supply chain for bulk chemicals.

A chemical plant (from now on denoted as the plant) uses large annual supplies of a bulk chemical. A number of suppliers deliver their parcels by short sea vessel to a transshipment point (TSP). Here, the chemical is stored using a third-party tank farm. Transportation from the TSP to the plant can be performed using either trucks or barges.

Since disruptions in the plant's production process are very expensive, buffer tank capacity at the plant site is required for sustained production and tolerance towards variations in supply.

Further transport to the plant used to be carried out by trucks but for a variety of reasons such as cost and safety aspects, as well as uncertainty caused by traffic congestion, the plant has moved to using a dedicated river barge instead. The supply chain is illustrated in Figure 1.
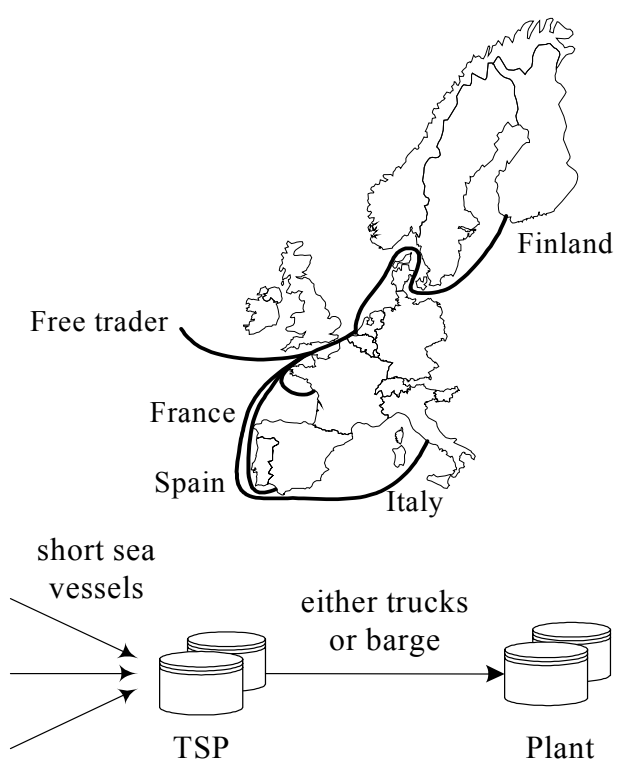

Figure 1: Supply Chain Overview

At scheduled times short sea vessels deliver parcels at the TSP which will be unloaded in the shore tanks. The tanks must have an appropriate capacity in order to deal with uncertainty regarding the arrivals of the vessels. 
Weather influences, but also a lack of coordination between the supply chain partners make the actual time of arrival (ATA) of vessels differ from their expected time of arrival (ETA). An example distribution function of the deviation in hours from the ETA is the following. If the deviation in hours is denoted as $x$, then:

$$
\begin{array}{ll}
\quad=\quad & \text { with } p=0.1 \\
U(-120,-48,48) & \text { with } p=0.8 \\
U(48,120) & \text { with } p=0.1
\end{array}
$$

where $U$ is the uniform distribution function. This means that $80 \%$ of the vessels arrive within plus or minus two days of their ETA; within this interval the probability density is constant. $10 \%$ of the vessels arrive between two or five days later and another $10 \%$ arrive between two or five days earlier than the ETA, in both cases also with constant probability density.

Figure 2 depicts the graph of this head-shoulder type distribution function. The deviations to the ETA cause the level in the shore tanks at the TSP to vary stochastically. For this reason, a safety stock level is maintained ensuring continued supply to the plant.

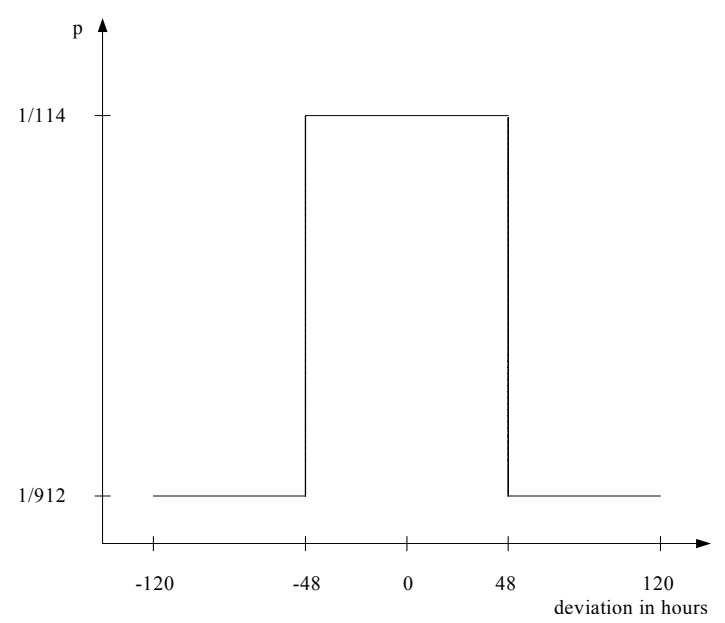

Figure 2: Distribution Function of the Deviation from the ETA of Short Sea Vessels

Below, the two modes for the onward transport from the TSP to the plant are discussed: road transport using trucks, and water transport using a barge.

\subsection{Transport by Trucks}

This supply process is characterized by a large number of small deliveries, as the constant daily intake of the plant is tens of times larger than the capacity of a single truck. The trucks pick up their cargo from the shore tanks at the TSP and shuttle between the plant and the TSP. This provides a steady stream of equidistantly spaced deliveries.

In this scenario, the tank farm at the TSP provides the primary buffer against disruptions in the supply by sea- going vessels. The buffer capacity at the plant is designed to accommodate small disruptions to the supply process from the TSP to the plant. The required tankage at the plant is therefore quite small.

\subsection{Transport by Barge}

A dedicated river barge carrying the same parcel size as the sea-going vessels provides a shuttle service from the TSP to the plant. This supply process features a smaller number of larger deliveries.

Using a river barge with the same parcel size as the sea-going vessels offers the opportunity to load the cargo directly from a vessel into the barge. This board to board loading is discussed in section 3.3. If board to board loading is not possible, the vessel will unload into, and the barge will load from the shore tanks.

The deliveries at the plant are stored in tanks. The cycles are stock-controlled (Van Asperen 2003a,b): the barge is scheduled to arrive at the plant when the stock in the tanks has reached the safety stock level.

The barge sails back and forth from the plant to the TSP. A cycle starts and ends at the plant when the barge arrives at the plant just before unloading. The cycle is defined to maximize the opportunity for board to board loading. Thus, both vessel and barge are scheduled to meet at the TSP somewhere in the middle of the cycle (the exact time depends on case-specific parameters). All this assumes that the plant can agree delivery dates with the suppliers according to the production plan.

Note that the return trip from plant to TSP is an empty run. In reality, the barge will sometimes use the idle time to transport cargo for another company.

\subsection{Board to Board Loading}

Board to board loading takes place if the short sea vessel and the river barge meet at the transshipment point. From the plant operator's point of view, this board to board loading is faster (no intermediate unloading and loading) and cheaper (less handling and storage capacity at the TSP is required). The supplier does not have a direct interest in board to board loading and he will therefore be willing to wait for a barge to arrive for a very limited time. Board to board loading requires close coordination among the partners in the supply chain to make sure that the ships meet at the appropriate time.

The probability of board to board loading can be defined as the fraction of the arrivals of the river barge at the transshipment point that result in board to board loading. It depends on the length of the time window in which the barge is at the transshipment point. Figure 3 illustrates this time window as a part of the cycle of the river barge.

The arrivals of the short sea vessels are scheduled somewhere in the middle of the cycle of the river barge. At. that moment the barge is waiting at the transshipment point 


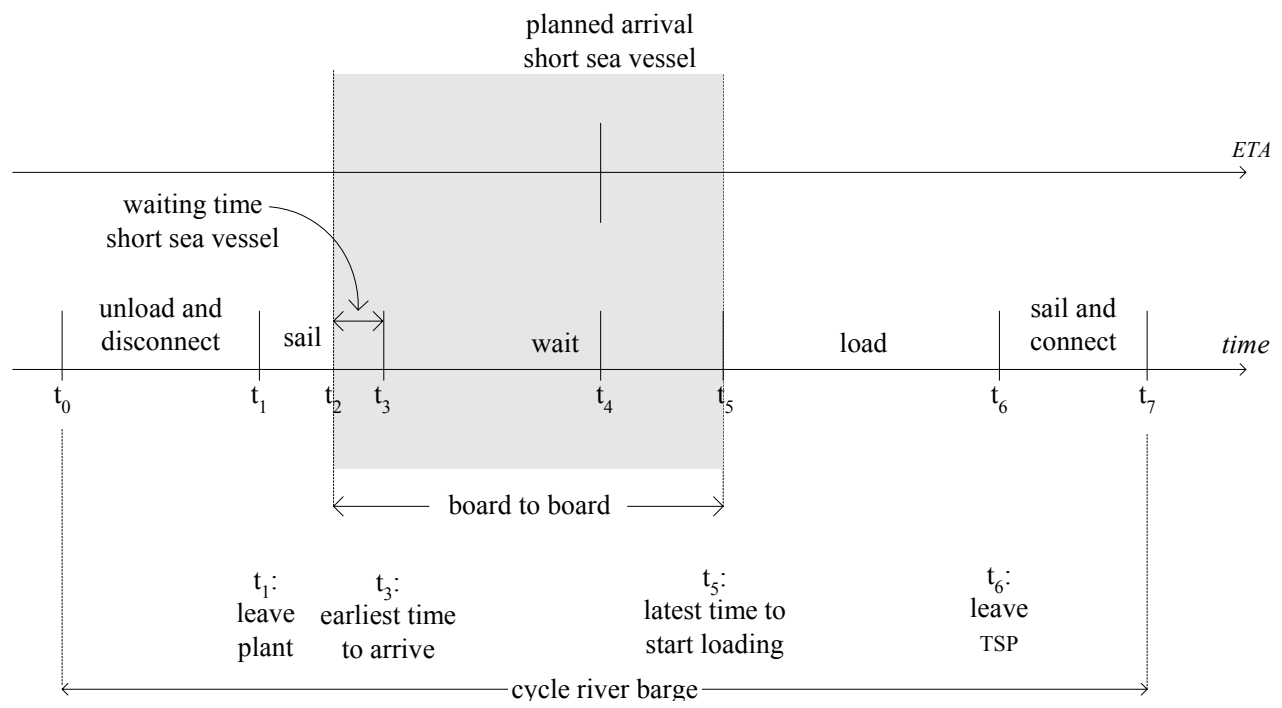

Figure 3: Time Window for Board to Board Loading

The time window during which board to board loading is possible, can be determined as follows (see also Figure 3).

$$
\begin{aligned}
\text { cycle }= & \text { unloading, disconnecting at plant, } \\
& + \text { sailing to TSP }+ \text { waiting time at TSP } \\
& + \text { connecting, loading, disconnecting at TSP } \\
& + \text { sailing to and connecting at plant }
\end{aligned}
$$

The planned arrival time for the short sea vessel is $t_{4}$. If the vessel arrives between $t_{2}$ and $t_{5}$, then board to board loading is possible. If the vessel arrives before $t_{2}$, the maximum waiting time for the vessel $\left(\mathrm{t}_{3}-\mathrm{t}_{2}\right)$ will make board to board loading impossible; if the vessel arrives after $t_{5}$, then the loading $\left(t_{6}-t_{5}\right)$ and sailing time $\left(t_{7}-t_{6}\right)$ for the barge will force it to load from the shore tanks in order to reach the plant in time (i.e., before the stock at the plant drops below the safety stock level).

\section{A CASE STUDY}

The chemical plant in this case study is located in the south-western region of The Netherlands. It is located about $50 \mathrm{~km}$ from Antwerp. Existing waterways connect the plant to the port of Antwerp. Roads to the plant site run through a densely populated area.

The plant uses 219 kiloton of a bulk chemical annually. There are five suppliers for reasons of price sensitivity and competition: Table 1 specifies the annual volumes of the contracts per supplier. Suppliers $S_{1}$ to $S_{4}$ are located at various remote sites in Europe and deliver their parcels by short sea vessel to the TSP at Antwerp. A dedicated river barge transports the bulk chemical to the plant. Short sea vessels and the barge carry 1,450 tons of bulk chemicals. A local supplier $\mathrm{S}_{\mathrm{L}}$ is located near the TSP at Antwerp and loads its parcels directly into the barge.
Table 1: Annual Volume of Contracts per Supplier

\begin{tabular}{ccc}
\hline Supplier & $\begin{array}{c}\text { Bulk Chemical } \\
\left(10^{3} \text { metric tons }\right)\end{array}$ & $\begin{array}{c}\text { Rounded } \\
\text { \% of total }\end{array}$ \\
\hline $\mathrm{S}_{1}$ & 14 & 6 \\
$\mathrm{~S}_{2}$ & 38 & 17 \\
$\mathrm{~S}_{3}$ & 22 & 10 \\
$\mathrm{~S}_{4}$ & 50 & 23 \\
$\mathrm{~S}_{\mathrm{L}}$ & 95 & 43 \\
\hline Total & 219 & 100
\end{tabular}

The (un)loading rate at the TSP is $150 \mathrm{ton} / \mathrm{hr}$. The barge shuttles between the plant and either the TSP or the supplier $\mathrm{S}_{\mathrm{L}}$. This takes four hours in each direction. The geographical layout is illustrated in Figure 4.

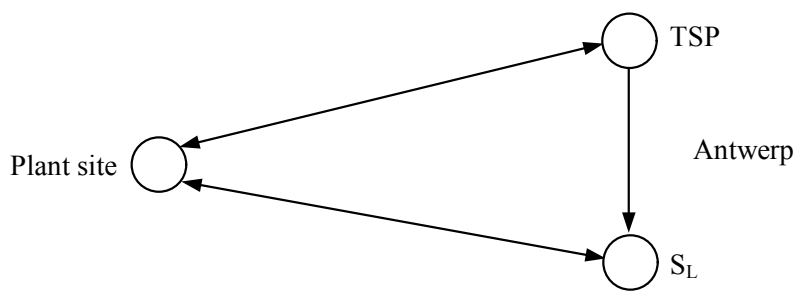

Figure 4: River Barge Sails between the Plant, and the TSP and Supplier $\mathrm{S}_{\mathrm{L}}$

If the barge can not load at the TSP (board to board is not possible and the shore tanks have insufficient stock), then the barge can pick up an emergency delivery at $\mathrm{S}_{\mathrm{L}}$ (this is part of the contract with this supplier). Sufficient stock is always available at $S_{L}$. Sometimes, in case of a possible overflow of the tanks at the TSP, the barge will skip a scheduled visit to $S_{L}$.

The deliveries at the plant are stored in tanks with a maximum capacity of 2,700 ton; the unloading rate is 200 ton/hr. The plant uses these tanks for a constant daily in- 
take of 620 ton. A safety stock level of 1,240 ton must be maintained.

The barge sails from the plant to Antwerp (either to TSP or $\mathrm{S}_{\mathrm{L}}$ ) and back. A cycle starts and ends when the barge arrives at the plant just before unloading. Given the plant's annual need for the bulk chemical as outlined in Table 1 and the transport capacity of the barge, the plant needs to be supplied three times a week. Consequently, the barge cycle has a length of 56 hours. A possible schedule is depicted in Figure 5. The ratio of visits to the TSP and $\mathrm{S}_{\mathrm{L}}$ (5:4) corresponds to the percentages in Table 1 (56\% and $44 \%$, respectively).

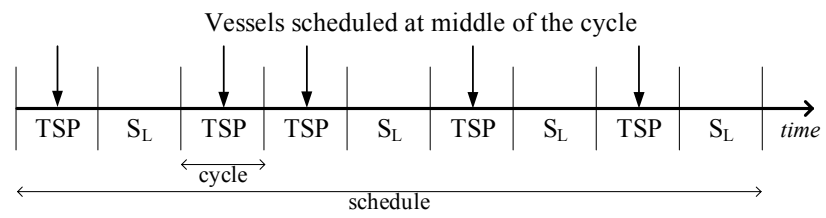

Figure 5: A Schedule of River Barge and Short Sea Vessels

If an incoming vessel does not meet a waiting barge, then the vessel will wait up to two hours for the barge to arrive. To maximize the opportunities for board to board loading, the barge will wait for a vessel until the latest possible moment. The barge does not have to wait for the actual arrival of the vessel: the ATA of vessels is known six hours beforehand.

Figure 6 provides an overview of vessel and barge operations. It shows the three locations (plant, TSP and $\mathrm{S}_{\mathrm{L}}$ ), and can be seen as divided into two parts. The left hand side describes the arrival of the vessel at the TSP whereas the right hand side shows how the barge sails either to the TSP or to $\mathrm{S}_{\mathrm{L}}$. In this flowchart, the vessel and the barge meet at the box Connect to vessel if the vessel is ready or will arrive soon. If possible, the vessel and barge will perform the board to board loading and disconnect: upon completion, the vessel leaves the system and the barge sails to the plant.

\section{A SIMULATION MODEL}

In section 3 we used a simplified model describing a base scenario of a supply chain for bulk chemicals. When applied to the case described in the previous section, it allows us to calculate the probability of board to board loading. This probability can only be determined analytically if a



Figure 6: Flow Chart of Barge Operations 
number of simplifying assumptions hold (see below). In reality, the supply chain is much more complicated and answers are hard to get analytically if these assumptions are dropped. For this reason a simulation model was developed which is outlined in section 5.1.

One simplifying assumption concerns the sailing times of the barge between the various locations. They were previously assumed to be constant (four hours) but this is not plausible. All kinds of delays can occur (e.g., caused by locks and weather) which affect the behavior of the supply chain.

Similar arguments hold with respect to a constant intake by the plant. Plant data show that quite regularly the intake is much less, sometimes up to $20 \%$. A varying intake can be caused by rejected deliveries or failures.

The impact of these kinds of events cannot easily be calculated analytically although it certainly affects the performance of the supply chain.

\subsection{Implementation Model}

Based on what is outlined in the previous section, a simulation model has been implemented in Enterprise Dynamics (Enterprise Dynamics 2003), a simulation package for discrete-event simulation. Simulation environments such as Enterprise Dynamics and Arena are generally easy to use, and allow for quick model construction. They provide built-in animation, generate statistics, and form well-tested simulation environments. The implementation model comprises various types of atoms, the Enterprise Dynamics equivalents of objects. Some of the atoms implement the simulation's logic, others hold the simulation data (tables), define the types of experiments or provide the desired output (e.g., graphs).

The scripting language of Enterprise Dynamics and the ability to open and close connections (known as channels in ED) between elements of the model were used in this implementation. The implementation of the rendezvous of vessels and barge with separate time-windows for both agents posed a particular challenge.

\section{EXPERIMENTS AND RESULTS}

We expect the efficiency of the logistics process to be sensitive to more intensive coordination by the plant. Improved coordination could for example reduce the 'head' window of the head-shoulder distribution described in section 3. As a consequence, one would expect the number of stock outs or overflows to decrease and the probability of board to board loading to increase.

Better flow management could also increase the performance of the barge. The barge as discussed in section 3.2 faces considerable idle time. At the TSP it may be waiting for many hours for a vessel that may not even show up in time. Improved coordination between partners in the supply chain could prevent such waiting times, enabling the barge to be deployed for other tasks.
In this paper, we focus on the effect of the improved coordination on the probability of board to board loading. To this end, we have performed a number of experiments with different time windows for the 'head' of the head-shoulder distribution, using both an analytical and a simulation-based approach. For the analytical approach, we maintain the simplifying assumptions mentioned in section 5 . The simulation-based approach uses stochastic sailing times from plant to TSP and $\mathrm{S}_{\mathrm{L}}$, but maintains the assumption of a constant intake at the plant. All experiments were conducted using a simulation run of twenty years to obtain statistically reliable results. Table 2 displays the results of both approaches. Here, the number $N$ represents the maximum deviation to the ETA of arrivals in the $80 \%$ section of the head-shoulder distribution function. As can be observed, the results of the analytical approach closely match the outcomes of the simulation experiments. Figure 7 shows the board to board probability results of the simulation experiments in a graph.

Table 2: Results of Analytical and Simulation Approach

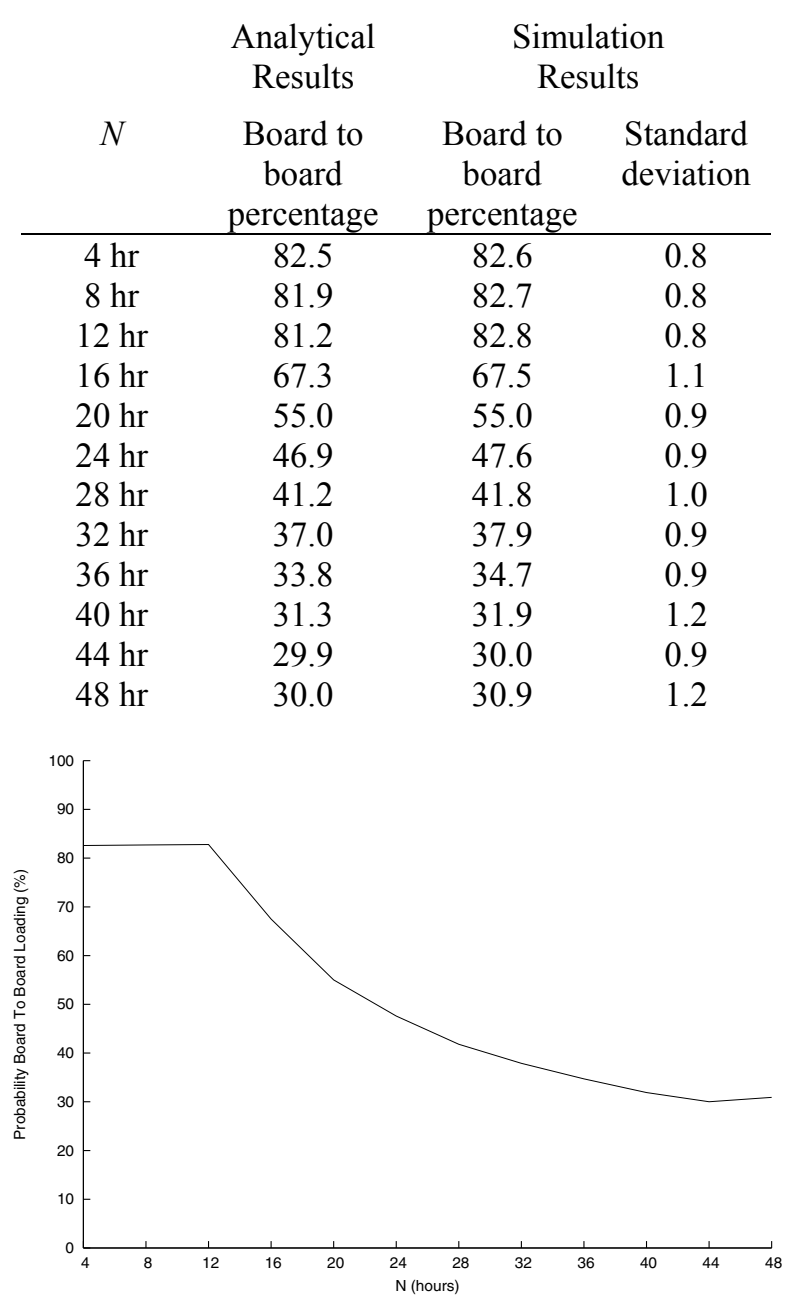

Figure 7: Board to Board Probability from Simulation Experiments 
Clearly, coordination efforts by the plant reducing the deviations to the ETA of the bulk (80 percent) of the vessels, positively impact the board to board percentage. However, below 12 hours, further reduction is pointless: the board to board percentage remains the same. This is due to the fact that if a vessel arrives within 12 hours of its ETA, it automatically (i.e., given the barge's schedule) arrives within the interval that the barge is ready and waiting for board to board loading. Since, according to the headshoulder distribution, this goes for at least 80 percent of the vessels (the other 20 percent is still somewhere between 120 hours early or 120 hours late), the board to board percentage should be at least 80 percent as well.

Another observation that can be made from the graph, is that when $N$ increases beyond the 40-hour limit, the board to board probability does not further deteriorate. This is due to the fact that at this point, many vessels start to arrive very early or late, to the extent that they will arrive within the board to board window of the previous or next barge cycle, thus still enabling board to board loading.

\section{CONCLUSION}

The results of the experiments conducted in this paper clearly demonstrate the beneficial influence of improved coordination on the logistics of a supply chain in the bulk chemical sector.

The simulation outcomes were confirmed by analytical calculations based on a number of simplifying assumptions. This provides a sound basis for future experiments with the simulation model, in which more of the simplifying assumptions can be dropped. We plan further experiments with variable plant intake and a more flexible barge schedule.

\section{REFERENCES}

Berger, Paul D., A. Gerstenfeld, and A.Z. Zeng (2004). How many suppliers are best? A decision-analysis approach. Omega, Vol. 32, pp. 9-15.

Chopra, S., and P. Meindl (2004). Supply Chain Management, 2nd ed., New Jersey: Prentice-Hall.

Enterprise Dynamics (2003). Documentation material. Incontrol Enterprise Dynamics. Contact: <http:// www . enterprisedynamics. com >.

Haehling von Lanzenauer, C.H., W.G. James, and D.D. Wright (1992). Insufficient supply in a natural gas distribution system: a risk analysis. European Journal of Operational Research, Vol. 56, No. 1, pp. 41-53.

Newhart, D.D., K.L. Stott, and F.J. Vasko (1993). Consolidating product sizes to minimize inventory levels for a multi-stage production and distribution system. Journal of the Operational Research Society, Vol 44, pp. 637-644.

Nieboer, R.A.J.J. and R. Dekker (1995). Brownian motion approximations for tankage assessment and stock con- trol. European Journal of Operational Research, Vol. 85, No. 1, pp. 192-204.

Silver, E.A. and R. Peterson (1985). Decision systems for inventory management and production planning. New York: John Wiley \& Sons.

Van Asperen, E., R. Dekker, M. Polman and H. de Swaan Arons (2003a). Modeling Ship Arrivals in Ports. In Proceedings of the Winter Simulation Conference 2003, S. Chick, P. J. Sánchez, D. Ferrin, and D. J. Morrice (Eds), pp. 1737-1744, New Orleans: Omnipress.

Van Asperen, E., R. Dekker, M. Polman and H. de Swaan Arons (2003b). Arrival Processes for Vessels in a Port Simulation, ERIM Report Series Research in Management, ERS-2003-067-LIS, Erasmus University Rotterdam, The Netherlands.

\section{AUTHOR BIOGRAPHIES}

HENK DE SWAAN ARONS is an associate professor at the Department of Computer Science of the Faculty of Economics at Erasmus University Rotterdam. He graduated in Applied Mathematics at Delft University of Technology in 1972. In 1991 he obtained his Ph.D. degree in computer science at Delft University of Technology. The thesis was mainly concerned with the design, applicability and applications of expert system tools. His research focuses on discrete-event and continuous simulation, with the emphasis on economical applications. His e-mail address is <deswaanarons@few.eur.nl>; his web address is <http://www. few.eur.nl/few/people/ deswaanarons/>.

EELCO VAN ASPEREN is an assistant professor at the Department of Computer Science of the Erasmus School of Economics at Erasmus University Rotterdam. He graduated in Business Computer Science at Erasmus University Rotterdam in 1993. Since January 2000 he is an assistant professor at Erasmus University Rotterdam. His research focuses on simulation with applications in logistics. You can reach him by e-mail at <vanasperen@few.eur.nl> and his web address is <http://www. few.eur.nl/ few/people/vanasperen/>.

ROMMERT DEKKER is a full professor in operations research at the Econometric Institute of Erasmus University Rotterdam. He obtained his M.Sc and Ph.D. in operations research at the State University of Leiden, and his M.Sc. degree in industrial engineering from Twente University of Technology. He worked with Shell for seven years on reliability and refinery logistics. His current research interests are in the fields of maintenance and logistics (inventory control, spare parts, ports, transportation, containers and reverse logistics). He has published over 60 papers in scientific journals and undertaken several case studies. His e-mail address is <rdekker@few.eur.nl>; his web address is 
$<$ http://www. few.eur.nl/few/people/

rdekker>.

MARK POLMAN graduated in Business Computer Science at Erasmus University Rotterdam in 1993. Since January 2000 he is an assistant professor at the Department of Computer Science of the Faculty of Economics at Erasmus University Rotterdam. Previous research areas include machine learning and communication modeling in distributed systems. His research focuses on discrete-event simulation. His e-mail address is <polman@few.eur.nl>; his web address is <http: //www. few.eur.nl/few/ people/polman>. 